\title{
Intrapersonal day-to-day travel variability and duration of house- hold travel surveys: Moving beyond the one-day convention
}

\section{Wei Li}

Texas A\&M University

wli@tamu.edu

\author{
Marlon G. Boarnet \\ University of Southern California \\ boarnet@usc.edu
}

\author{
Douglas Houston \\ University of California, Irvine \\ houston@uci.edu \\ Han Park \\ Texas A\&M University \\ hpark@tamu.edu
}

\begin{abstract}
By analyzing seven-day travel logs from Los Angeles during 2011-2013, we contribute to the understanding of intrapersonal dayto-day travel variability (IDTV) in relation to socio-demographic and land-use characteristics and the implication of travel survey duration for travel parameter estimates. Our main sample included 2,395 person-days from 352 individual participants in 219 households. Our analytical methods included linear regressions and random sampling experiments.

Our Feasible Generalized Least Squares (FGLS) regression models revealed that many factors significantly influenced IDTV, such as gender, age, income, and household type. However, the observed socio-demographic and land-use characteristics could only explain a small portion of IDTV. The random sampling experiments enabled us to contrast travel variables measured from the seven-day master sample with those from subsamples of a shorter period (one to six days). The "optimal" duration for a travel survey may depend on the specific travel variables measured, and we provide evidence that studies of transit and non-motorized travel will require longer surveys than studies of car travel.

In conclusion, the conventional one-day approach is likely to produce imprecise parameter estimates due to the intrapersonal day-today travel variability. We recommend that transportation professionals and policy makers consider shifting from the conventional one-day approach toward a multi-day approach. Surveys that focus on the modes of walking, biking, and transit should consider data collection for at least seven days.
\end{abstract}

Keywords: Intrapersonal day-to-day travel variability, transit accessibility, household travel survey, survey duration, random sampling experiments

\section{Article history:}

Received: October 29, 2016

Received in revised form:

December 15, 2017

Accepted: March 14, 2018

Available online: November 27, 2018

Copyright 2018 Wei Li, Douglas Houston, Marlon G. Boarnet \& Han Park http://dx.doi.org/10.5198/jtlu.2018.984

ISSN: 1938-7849 | Licensed under the Creative Commons Attribution - Noncommercial License 4.0

The Journal of Transport and Land Use is the official journal of the World Society for Transport and Land Use (WSTLUR) and is published and sponsored by the University of Minnesota Center for Transportation Studies. This paper is also published with additional sponsorship from WSTLUR. 


\section{Introduction}

Travel surveys are a fundamentally important tool for studying interactions between transport and land use. The choice of travel survey duration, which partly depends on how researchers perceive variation in individual travel behavior, has important implications for the precision of estimates. The single-day travel survey (SDTS), in which each individual or household reports travel activity for only one day, represents the archetypal data collection duration among travel surveys conducted at the national, state or regional levels. This is partly due to the higher cost of carrying out multi-day travel surveys (MDTS). The basic assumption in the conventional SDTS approach is that travel activities have repetitive patterns from day to day, and if travel is reported for a randomly chosen day out of some longer period, then an unbiased sample of behavior for that period can be obtained (Pas \& Sundar, 1995; Stopher \& Zhang, 2011). During the 1980s, researchers such as Pas $(1983,1986,1987)$ explored the intrapersonal variability in travel and suggested that multi-day travel surveys (MDTS) produce a higher level of precision than SDTS. Recent studies such as Stopher and Zhang (2011) and Venter and Joubert (2013) also challenged the above assumption of daily repetitive travel patterns. However, empirical studies directly evaluating the performance of SDTS and MDTS have been very rare, partly due to the scarcity of multiday data.

In this paper, we extend the literature in two ways. First, we demonstrate that the variation in individual travel behavior across days itself varies across different travel modes. Our measures of survey subjects' variation in travel across a seven-day survey show that different modes (car, transit, walking, and bicycling) display different patterns of day-to-day variation. This suggests that simple weighting strategies which may attempt to recover multi-day travel from single-day surveys will not perform equally well for several travel variables at once. Second, the question of a single- or multi-day travel survey is important for land-use and travel researchers. Non-motorized trips, increasingly an area of focus of land use - travel surveys, are particularly sensitive to day-to-day intra-personal variation, and hence the single-day survey approach is likely least appropriate for non-motorized travel. Additionally, land-use variables themselves — in our case access to a new light rail transit system — are associated with daily variation in travel behavior.

In this paper, our analysis focuses on the intrapersonal day-to-day travel variability (IDTV) in a seven-day travel survey sample from the city of Los Angeles during 2011-2012. In the next section, we review the literature in which the measurement and characteristics of IDTV were discussed and studies based on MDTS were summarized. We introduce our data and analytical methods in Section 3, followed by results (Section 4) regarding our investigation of IDTV and the impact of travel survey duration on the estimates of trip-making characteristics. In Section 5, we discuss the contribution and limitation of our study.

\section{$2 \quad$ Literature review}

Early examples of MDTS include the 1965 Great Britain and 1966 France national travel surveys of a one-week data collection period (Stopher, Zhang, Armoogum, \& Madre, 2011), the 1971 Uppsala (Sweden) travel survey of a five-week data collection period (Hanson, 1982; Hanson \& Hanson, 1981; Marble, Hanson, \& Hanson, 1972), the 1973 Reading (UK) activity survey covering seven days (Shapcott, 1978), as well as the 1978 Oxford (UK) car use survey (Goodwin, 1978) which analyzed a sample of seven-day travel diaries. Stopher, Kockelman, Greaves, \& Clifford (2008) presented a summary of 13 multi-day travel studies during 1971-2006; the data collection period of these studies ranged from 2 to 42 days. In Table 1, we summarize the multi-day travel surveys that were completed after 2000; these 
surveys, also ranging from 2 to 42 days, commonly relied on a travel diary as the main data collection instrument. Most of the studies in Table 1 emphasized variations in trip mode, purpose and time. However, the number of MDTS studies was relatively small compared to the vast literature using one-day surveys. Since the mid-1960s, the survey duration for most of the household travel surveys worldwide has been one day, especially those employed to support transportation modeling and planning (Stopher et al., 2008; Stopher et al., 2011).

Pas $(1986,1987)$ conceptually categorized variability in travel behavior as interpersonal variability (differences between individuals in their travel behavior) and intrapersonal variability (day-to-day and within-day differences in individuals travel behavior). Based on the analysis of the 1973 Reading survey, Pas (1986) argued that multi-day samples could provide benefits in improving the estimation precision of trip-making characteristics. Using the same dataset, Pas (1987) found that intrapersonal variability could explain about half of the total variability in travel behavior; further, intrapersonal variability was more substantial in the case of maintenance and leisure trips than in the case of subsistence trips. Summarizing case studies in Hong Kong (Harrison, 1986), Oxford (Goodwin, 1978), and Adelaide (Barnard, 1984), Jones and Clarke (1988) concluded that the measurement of intrapersonal variability had important implications concerning travel demand management and policies; they noted that one-day travel data, even those with large sample sizes, could not be used to reveal variations in travel over time.

Table 1: Recent multi-day household travel surveys

\begin{tabular}{|c|c|c|c|c|c|}
\hline Country/Region & Year & Sample Size & Survey Instrument & Main Focus & $\begin{array}{l}\text { Survey Dura- } \\
\text { tion (Day) }\end{array}$ \\
\hline Thurgau, Switzerland & 2003 & $\begin{array}{l}99 \text { Households } \\
\text { (HHs) }\end{array}$ & Travel diary & Travel; leisure & 42 \\
\hline Toronto, Canada & 2003 & $262 \mathrm{HHs}$ & $\begin{array}{l}\text { Travel and activity } \\
\text { survey }\end{array}$ & $\begin{array}{l}\text { Spatial-temporal } \\
\text { variability in } \\
\text { activity-travel } \\
\text { behavior }\end{array}$ & 7 \\
\hline Michigan & 2004-2005 & $14,315 \mathrm{HHs}$ & $\begin{array}{l}\text { Computer Assisted } \\
\text { Telephone Inter- } \\
\text { view }\end{array}$ & $\begin{array}{l}\text { Travel mode, trip } \\
\text { count/purpose/ } \\
\text { destination }\end{array}$ & 2 \\
\hline South Australia & $2005-2006$ & $\begin{array}{l}\text { HHs: 50/46/36 } \\
\text { (Wave 1/2/3) }\end{array}$ & GPS logs & $\begin{array}{l}\text { Travel time and } \\
\text { distance; trip } \\
\text { counts }\end{array}$ & 28 \\
\hline $\begin{array}{l}\text { Cities of Amersfoort, } \\
\text { Veenendaal, and Zee- } \\
\text { wolde in Netherland }\end{array}$ & 2007 & 1,104 persons & GPS logs with GIS & $\begin{array}{l}\text { Travel time, } \\
\text { mode and } \\
\text { purpose }\end{array}$ & 7 \\
\hline Hanoi, Vietnam & 2010 & $47 \mathrm{HHs}$ & Travel diary & $\begin{array}{l}\text { Commuting } \\
\text { travel }\end{array}$ & 7 \\
\hline Portland, Oregon & 2010-2011 & $323 \mathrm{HHs}$ & GPS logs & $\begin{array}{l}\text { Travel destina- } \\
\text { tions and mode }\end{array}$ & 5 \\
\hline $\begin{array}{l}\text { UK (National Travel } \\
\text { Survey) }\end{array}$ & Ongoing & $\begin{array}{l}\text { Around 7,000 HHs } \\
\text { in } 2014\end{array}$ & Travel diary & $\begin{array}{l}\text { Travel mode, pur- } \\
\text { pose and time; } \\
\text { trip count }\end{array}$ & 7 \\
\hline $\begin{array}{l}\text { Germany (German } \\
\text { Mobility Panel) }\end{array}$ & Ongoing & $\begin{array}{l}\text { More than } 1,500 \\
\text { HHs per year since } \\
2010\end{array}$ & Travel diary & $\begin{array}{l}\text { Travel mode, pur- } \\
\text { pose and time }\end{array}$ & 7 \\
\hline
\end{tabular}

Note: information for the above table was gathered from various sources (Bohte \& Maat, 2009; Buliung, Roorda, \& Remmel, 2008; Karlsruhe Institute of Technology, 2015; Löchl, Axhausen, \& Schönfelder, 2005; Michigan Department of Transportation, 2005; Stopher, Clifford, \& Montes, 2008; Tran, Chikaraishi, Zhang, \& Fujiwara, 2012; UK Department of Transport, 2016). 
Based on the six-week travel diary data collected in cities of Halle and Karlsruhe in Germany, Bhat, Frusti, Zhao, Schönfelder, \& Axhausen (2004) revealed several important determinants of the regularity and frequency of shopping activities. The same data were later used by Bayarma, Kitamura, \& Susilo (2007), who analyzed the recurrence characteristics of five representative daily travel patterns (i.e., public transport commuting, car-based multiple visits, shopping \& leisure, accompanying and work). Dill and Broach (2014) identified common travel destinations by using stated data and revealed data of fiveday Global Positioning System (GPS) logs from Portland, Oregon (USA); they confirmed significant variation in travel over multiple days and found that even the duration of five days was not sufficient to capture some common destinations. Based on the four-week GPS logs from 50, 46 and 36 households in Adelaide (Australia) in three waves respectively, Stopher et al. (2008) found that travel characteristics calculated from the first one, two or three days of data were highly unstable among the three waves. From the same dataset, Stopher and Zhang (2011) questioned the conventional one-day approach by finding relatively little repetition of tours from one day to the next.

While previous studies have challenged the single-day approach, we contribute additional evidence to the question of the appropriate number of survey days. Our results show that IDTV is larger, compared to sample average trip frequencies, for non-motorized travel. We further show that new light rail transit is associated with IDTV, implying a potential association between the built environment and the appropriate number of days for a travel survey. We also show that the appropriate number of survey days (using measures formalized later in this paper) will vary for different travel behaviors, with transit and non-motorized travel requiring longer duration surveys. The net effect of these three findings raises the importance of a land-use and travel-behavior perspective on IDTV, something that we believe has not been emphasized in the literature.

\section{$3 \quad$ Methodology}

\subsection{Data}

This study mainly analyzed the 7-day travel log data from the first data collection phase (September 2011 to February 2012) of a three-year longitudinal travel and activity study in the Crenshaw and Exposition corridors of south Los Angeles, California. The study area map was published in Spears, Houston, $\&$ Boarnet (2013) and the layout and content of the travel log template were published in Houston, Luong, \& Boarnet (2014).

To identify potential participant households, the authors purchased a list of all household addresses $(27,275)$ within the study area from InfoUSA, a professional firm providing mailing lists and other marketing information. Each household was mailed a letter inviting them to take part in the study. A total of 651 households indicated an interest in participating our study, and 285 households returned a complete set of 7-day travel logs. These logs, which were designed to be carried by all household members over 12 years of age ( 499 individuals), were used to record their daily trip counts for each of the following modes: private vehicle as a driver, private vehicle as a passenger, motor-cycle / scooter, bus, train, bicycle and walking. For bicycle and walking trips, participants were also asked to log their daily total trip duration in minutes. In this study, a trip is defined as one-way only. Previous research suggests that requiring participants to report multiple days of travel and activity information could represent a substantial burden (Harvey, 1993; Pas \& Harvey, 1997; Schlich \& Axhausen, 2003). However, according to Jara-Díaz and Rosales-Salas (2015), the effect of travel survey duration on response rate might still be inconclusive due to lack of rigorous empirical comparisons.

Our response rate from households that indicated initial interest was 44\% (285/651) and 1\% $(285 / 27,275)$ if calculating the rate using all households we contacted by mails at the beginning. Our 
response rate of $1 \%$ was comparable to the response rate of $1.4 \%$ in the $2010-2012$ California Household Travel Survey (for Los Angeles and Ventura counties), which required participants to record only one day of travel data (California Department of Transportation, 2013). Further, a 2012 survey of households in Los Angeles County only obtained a response rate of $0.4 \%$ (Houston, Boarnet, Ferguson, $\&$ Spears, 2015).

Our final sample included 2,395 person-days from 352 individuals in 219 households which provided complete responses for the following socio-demographic characteristics: age, education, income, employment status, gender, household car ownership, household size, and number of persons under 18 years of age. Person-days were eliminated if the day of a week was missing; we further ruled out person-days if a missing or extremely large value was detected for the trip count variables or the duration of walking/biking. ${ }^{1}$ Spears et al. (2013) described the area based on census data as being generally low-income and non-white: the percentages of population being African American, Hispanic and NonHispanic White are 43\%, 41\%, and 9\% respectively; approximately $20 \%$ of the residents were under the poverty line, and $24 \%$ of the residents received a bachelor's degree or higher.

During September 2012-January 2013, about two-thirds of the above individuals completed a follow-up study following the same protocol; participants in the follow-up study share similar sociodemographic characteristics with the above research (Hong, Boarnet, \& Houston, 2016). The follow-up study was scheduled after a light rail transit (LRT) line named EXPO Line became open in April 2012 and offered us 1,824 valid person-days from 266 individuals in 171 households. Data from the followup study were used in a supplemental analysis to better understand the influence of socio-demographic and land-use factors on IDTV. ${ }^{2}$

Since previous studies including Jara-Díaz and Rosales-Salas (2015), Axhausen Axhausen, Zimmerman, Schönfelder, Rindsfüser, and Haupt (2002), and Golob and Meurs (1986) suggest that longer periods of travel survey might be associated with fatigue in reporting, we utilized the method proposed by Golob and Meurs (1986) and investigated the risk of reporting fatigue in two steps. First, we generated a 7 by 7 matrix in which the number of person-days with a missing trip count record is tabulated by the day of week (matrix column: Monday-Sunday) and the sequential day of the seven-day period ${ }^{3}$ (matrix row: $1^{\text {st }}$ to $7^{\text {th }}$ day); for any particular day of the week (i.e., Monday-Sunday), we did not notice a trend that the number of person-days with a missing trip record increases as the sequential day number increases. Second, we investigated the scatter plot between average daily total trip count and the sequential day number for each day of the week (i.e., Monday-Sunday), and generally found little evidence that the average daily trip count becomes smaller if it is reported as the later days of the seven-day period ${ }^{3}$. Houston, Luong, and Boarnet (2014), who verified the trip reporting quality based on a subset of this study sample with GPS tracking data, confirmed good agreement between the trip counts derived from the GPS tracking data and the participants' self-reported travel log data. To further mitigate the risk of reporting fatigue, we ensured that participants whose reporting days were fewer than six were not included in the final sample.

\subsection{Measuring Intrapersonal Day-to-Day Travel Variability (IDTV)}

Table 2 presents the summary statistics of the travel-related variables, individual characteristics, and the household characteristics. The sample characteristics are generally consistent with the socio-demograph-

${ }^{1}$ In order to identify outliers, we used the 99th percentile thresholds: 15 for total daily trips, 12 for daily private vehicle trips, 6 for daily bus/train trips, 6 for daily walking/biking trips, and 180 for the total duration of walking/biking trips.

${ }^{2}$ The supplemental analysis follows Equation 2. Table 4 reports results of the supplemental analysis side by side with the main study.

${ }^{3}$ However, we noticed that average daily total trip count for Sunday was 4.5 ( $1^{\text {st }}$ day), 4.5 ( $2^{\text {nd }}$ day), 3.7 ( $3^{\text {rd }}$ day), 3.9 ( $4^{\text {th }}$ day), 3.3 ( $5^{\text {th }}$ day), 2.8 ( $6^{\text {th }}$ day), and 2.9 ( $7^{\text {th }}$ day). 
ic characteristics of the study area. About $55 \%$ of the participants had a household income less than $\$ 55,000 ; 41 \%$ of the participants had a full-time job; $63 \%$ of the participants were female; the percentages of senior ( $\geq 65 \mathrm{yrs}$ ) and minor (12-17 yrs) participants were $14 \%$ and $9 \%$ respectively.

We assessed intrapersonal day-to-day variability in five travel metrics: daily total number of trips, daily total number of private vehicle trips, daily total number of bus/train trips, daily total number of walking/biking trips and daily total duration of walking/biking trips. For this analysis, we follow Elango, Guensler, and Ogle (2007) and Stopher (2012) and measure IDTV as follows ${ }^{4}$ :

$\Delta \mathrm{T}_{i, d, m}=\left|\mathrm{T}_{i, d, m}-\overline{\mathrm{T}}_{i m}\right|$

where

- $\quad i$ is a person identification number;

- $d E[1,7]$ represents the day of travel $(1=$ Monday, $2=$ Tuesday, $\ldots, 6=$ Saturday and $7=$ Sunday $)$;

- $m E[1,5]$ represents the five travel metrics analyzed;

- $\quad T_{i, d, m}$ is the value of variable $m$ for person $i$ on day $d$;

- $\quad \overline{\mathrm{T}}_{i m}$ is the average value of variable $m$ for person $i$ during the seven-day period.

Table 2: Summary statistics of key variables

\begin{tabular}{|c|c|c|c|c|}
\hline Variable & Mean & Std. Dev. & Min & $\operatorname{Max}$ \\
\hline \multicolumn{5}{|l|}{ Variables about Daily Travel } \\
\hline Total Number of Trips & 3.9382 & 2.6816 & 0 & 15 \\
\hline Total Number of Private Vehicle Trips & 2.7424 & 2.4208 & 0 & 12 \\
\hline Total Number of Bus/Train Trips & 0.2894 & 0.9164 & 0 & 6 \\
\hline Total Number of Walking/Biking Trips & 0.8768 & 1.2771 & 0 & 6 \\
\hline Total Duration of Walking/Biking Trips (Minutes) & 15.4990 & 26.5393 & 0 & 180 \\
\hline \multicolumn{5}{|l|}{ Individual Characteristics (Indicator 1 or 0 ) } \\
\hline Person is male & 0.3712 & 0.4832 & & \\
\hline Person is $12-17$ yrs & 0.0877 & 0.2829 & & \\
\hline Person is senior citizen ( $\geq 65 \mathrm{yrs}$ ) & 0.1415 & 0.3487 & & \\
\hline Person is employed part-time & 0.1900 & 0.3924 & & \\
\hline Person is employed full-time & 0.4142 & 0.4927 & & \\
\hline \multicolumn{5}{|c|}{ Transit Accessibility and Household Characteristics (Indicator 1 or 0) } \\
\hline Living within $1 / 2$ mile of LRT station & 0.4367 & 0.4961 & & \\
\hline Household has at least one vehicle & 0.9248 & 0.2637 & & \\
\hline Household Annual Income > \$55k & 0.4568 & 0.4982 & & \\
\hline Household has at least 3 persons & 0.4376 & 0.4962 & & \\
\hline Household has minor (under $18 \mathrm{yrs}$ ) & 0.3695 & 0.4828 & & \\
\hline \multicolumn{5}{|l|}{ Day of the Week (Indicator 1 or 0 ) } \\
\hline Travel Data for Monday & 0.1420 & 0.3491 & & \\
\hline Travel Data for Tuesday & 0.1445 & 0.3516 & & \\
\hline Travel Data for Wednesday & 0.1449 & 0.3521 & & \\
\hline Travel Data for Thursday & 0.1441 & 0.3512 & & \\
\hline Travel Data for Friday & 0.1436 & 0.3508 & & \\
\hline Travel Data for Saturday & 0.1436 & 0.3508 & & \\
\hline Travel Data for Sunday & 0.1374 & 0.3443 & & \\
\hline
\end{tabular}

Note: The final sample included a total of 2,395 person days from 352 participants in 219 households, who recorded seven consecutive days of travel data during September 2011-February 2012. At least six days of data were valid for each participant.

${ }^{4}$ We also experimented in measuring IDTV as $\frac{\left|\mathrm{T}_{i, d, m}-\overline{\mathrm{T}}_{i, m}\right|}{\overline{\mathrm{T}}_{i, m}}$ but decided not to adopt this approach due to the occurrence of computational error when $\overline{\mathrm{T}}_{i, m}$ is zero. 
Previous researchers have explored different methods in measuring intrapersonal day-to-day travel variability, such as the variance of trip distance, time and frequency (Hanson \& Huff, 1981; Pas, 1987; Pas \& Koppelman, 1987; Pas \& Sundar, 1995; Stopher et al., 2008). Compared to these methods, our choice as illustrated in Equation 1 can best accommodate our data structure and allow us to measure the deviation of a certain person-day from the 7-day mean of the same person. ${ }^{5}$ While Elango et al. (2007) described IDTV with regards to different demographic subgroups, we built the following linear modeling framework to explain the effects of various factors on IDTV while controlling for confounding variables. We interpret IDTV as a function of observable variables:

$\Delta \mathrm{T}_{i, d, m}=f\left(\mathbf{I}_{i}, \boldsymbol{H}_{i}, D_{i, d}, e_{i, d}\right)_{m}$

where

- $I_{i}$ is a vector of individual characteristics for person $i$;

- $\quad H_{i}$ is a vector of household characteristics for person $i^{6}$;

- $D_{i, d}$ is an indicator variable, which was assigned the value of one if travel data of person $i$ were collected from day $d$, and the value of 0 otherwise;

- $e_{i, d}$ is the error term.

We used the Variance Inflation Factor (VIF) to assess the potential risk of multicollinearity. The VIF scores, which ranged from 1.03 to 2.59 , were much smaller than the widely used threshold of 10 (Kennedy, 2008). Therefore, we concluded that the risk of threat from multicollinearity was low for our study. As each participant is represented multiple times in our dataset, we chose the Feasible Generalized Least Squares (FGLS) estimator (Stata, 2017; Wooldridge, 2006; p 424-426) to address the repeatedobservation issue. To illustrate our modeling approach, we use $\mathbf{Y}$ to denote a vector of IDTV for one of the five travel metrics for all observations, and $\mathbf{X}$ to denote a matrix of all observed characteristics; then the FGLS estimates are:

\section{$\hat{\boldsymbol{\beta}}_{\mathrm{FGLS}}=\left(\mathbf{X}^{\prime} \hat{\mathbf{\Omega}} \mathbf{X}\right)^{-1} \mathbf{X}^{\prime} \hat{\mathbf{\Omega}}^{-1} \mathbf{Y}$}

$\hat{\mathbf{\Omega}}$ is the estimated variance matrix of the error term $\mathrm{e}_{i, d}$, and it is defined as follows:

$$
\boldsymbol{\Omega}=\left[\begin{array}{ccc}
\sigma_{1}^{2} \mathbf{I}_{1} & \mathbf{0} & \mathbf{0} \\
\mathbf{0} & \sigma_{2}^{2} \mathbf{I}_{2} & \mathbf{0} \\
& & \\
\mathbf{0} & \mathbf{0} & \sigma_{n}^{2} \mathbf{I}_{n}
\end{array}\right]
$$

where:

- $\sigma_{1}^{2}$ is the variance for person $i$;

- $\mathbf{I}_{i}$ is a matrix that describes the structure of relationships among different days for person $i$.

As illustrated above, we regarded our dataset as panel data, assuming heteroscedasticity across different persons. We also assumed the correlation of error terms among different days within a person; the correlation parameter was considered unique for each person. We used $x+g l s$ of the Stata software to operationalize the analysis (Stata, 2017).

\footnotetext{
${ }^{5}$ We also measured IDTV in alternative forms such as the square of $\Delta \mathrm{T}_{i \cdot d m}$, and logarithm of $\Delta \mathrm{T}_{i \cdot d m}$. We estimated our regres sion models with these alternative measures and obtained similar results as in Table 4.

'The variable, which indicates whether a person lives within $1 / 2$ mile of LRT station' is included only in the follow-up study.
} 


\subsection{Random sampling experiments}

Since observable characteristics can only explain a small portion of IDTV (as measured by R-squared), which may be largely due to randomness, we decided to employ the random sampling (RS) experiments to generate alternative insights on IDTV and contrast the key travel metrics measured for the full sevenday data collection period with randomly-selected subset of days (one to six days). We conducted RS experiments on the main-study sample (352 participants) only. We did not conduct them on the followup study sample (266 participants) because its participants had already completed the main study and its sample size was smaller than the main study due to attrition.

The RS experiment is a technique to draw random samples or to simulate random events. Previous researchers have used it in the fields such as civil engineering (Chen, Yang, Lo, \& Tang, 1999; Li, 1994), environmental management (Carmel, Paz, Jahashan, \& Shoshany, 2009; Chang, Parvathinathan, \& Breeden, 2008) and urban planning (Xian \& Crane, 2005). Our random sampling experiments and analysis were carried out in the following procedure:

- Step 1: For each of the 352 individual participants, randomly draw days $(\mathrm{n}=1,2,3,4,5$, or 6) out of the seven days, and compile these records to form a subsample; a total of 1,000 subsamples were independently generated using this protocol;

- Step 2: Calculate key statistics (including mean, median, standard deviation, maximum and minimum) for each ( $m E[1,5])$ of the five travel metrics for each subsample.

For the 69 individuals who had only six valid days of data, we assigned an additional blank personday record, so all individuals in this stage of analysis had records for seven days. The addition of this "blank" person-day is consistent with our approach given our assumption that some participants in an actual travel survey may return an invalid, inaccurate or missing record on one of their travel days and this may happen randomly. In our RS procedure, the blank record had the same probability of being drawn as a valid record.

When planning for a one-day survey, practitioners generally assign a dedicated day for each household; such practices aim to ensure that the number of survey days for each day of a week (Monday, Tuesday, Wednesday,..., Sunday) is similar. For each experiment following the above RS procedure, we could also obtain a similar number of days for each day of a week. In Appendix 1, we present the means and standard deviations of each day's fraction in each of our RS experiments, using one-day RS experiments as an example (see Table A-1). We also designed a constrained random sampling procedure, in which we ensure the number of survey days drawn for each day of a week is the same (i.e., each of the 1,000 experiments has 50 survey days for Monday, Tuesday, Wednesday,..., Sunday). Our RS procedure and the constrained procedure generate very similar results for the five travel metrics (see Table A-2 and Figure A-1 in Appendix 1).

\section{$4 \quad$ Results}

\subsection{Effects of observed characteristics on intrapersonal day-to-day travel variability}

The summary IDTV statistics based on Equation 1 are presented in Table 3. We found that the magnitude of IDTV was large concerning the sample means of the actual travel variables (see Table 2); this was generally consistent with Pas (1987). The average IDTV for the daily total number of trips was 1.33 trips, which was $34 \%$ of this travel variable's sample mean (3.94). The average IDTV for the private vehicle mode was 1.06 trips (39\% of this variable's sample mean), compared to 0.20 trips for bus/train ( $70 \%$ of this variable's sample mean), and 0.51 trips for walking/biking $(59 \%$ of this variable's sample 
mean). The IDTV for the daily duration of walking/biking was 9.92 minutes - about $64 \%$ of the variable's sample mean.

Table 3: Intrapersonal day-to-day travel variability

\begin{tabular}{|l|c|c|c|c|c|c|}
\hline \multicolumn{1}{|c|}{$\Delta \mathbf{T}_{\boldsymbol{i}, \boldsymbol{d} \boldsymbol{m} \boldsymbol{m}}$} & Mean & $\begin{array}{c}\text { 95\% C.I. } \\
\text { Lower }\end{array}$ & $\begin{array}{c}\text { 95\% C.I. } \\
\text { Upper }\end{array}$ & $\begin{array}{c}\text { Pop. } \\
\text { Std. Dev. }\end{array}$ & Min & Max \\
\hline Total Number of Trips & 1.3266 & 1.2741 & 1.3791 & 1.3101 & 0 & 10.29 \\
\hline Total Number of Private Vehicle Trips & 1.0616 & 1.0166 & 1.1067 & 1.1245 & 0 & 10.29 \\
\hline Total Number of Bus/Train Trips & 0.2007 & 0.1783 & 0.2230 & 0.5574 & 0 & 4.86 \\
\hline Total Number of Walking/Biking Trips & 0.5143 & 0.4876 & 0.5410 & 0.6657 & 0 & 5 \\
\hline Total Minutes of Walking/Biking Trips & 9.9241 & 9.3229 & 10.5254 & 15.0024 & 0 & 133.57 \\
\hline
\end{tabular}

Note: See Equation 1 for the formula of $\Delta \mathrm{T}_{i, d}, m$; based on 2,395 person-days. We present the $95 \%$ confidence intervals for the means, as well as the estimated population standard deviations.

The FGLS models (shown under the "Main Study" columns of Table 4) revealed insights that serve our study purpose from some perspectives. First, we found a number of factors that significantly influenced IDTV. For example, male participants showed larger IDTV than female in terms of transit and walking/biking trip counts; compared to adults of 18-64 years, the young and elderly participants were associated with smaller IDTV for almost all travel variables, except for walking/bike trip counts for which the young participants had more IDTV than those of 18-64 years. Persons from a household with at least one car (or income $>\$ 55,000$ ) generated larger IDTV for private vehicle trips, and smaller IDTV for bus/train and walking/biking trips and walking/biking duration than those in a carless household (or income $\leq \$ 55,000$ ). Generally speaking, the IDTV for Monday was significantly less than other days of the week, and the IDTV was greater during Saturday and Sunday than during the weekdays.

Second, we noticed that the observed characteristics could only explain a small portion of IDTV, as measured by R-squared (see "Main Study" columns of Table 4): 3\% for the total trip count, 5\% for the private vehicle trip count, $13 \%$ for the bus/train trip count, $5 \%$ for the walking/biking trip count, and $5 \%$ for the duration of walk/biking. There was a tremendous amount of residual IDTV that was hard to explain by observable characteristics; consistent with the previous studies such as Jones and Clarke (1988) and Dill and Broach (2014), our results showed that the validity of results relying on single-day surveys might be subject to imprecision due to negligence of IDTV. We also estimated Equation 2 using the square of $\Delta \mathrm{T}_{i, d, m}$ and the logarithm of $\Delta \mathrm{T}_{i, d, m}$ as alternative dependent variables, and obtained similar results with the current OLS modeling approach in terms of sign-and-significance patterns.

The supplemental analysis revealed some similarities and some differences in results after the new light rail service opened (see "Follow-up Study" columns of Table 4.) Living within $1 / 2$ mile of a new light-rail station is associated with larger IDTV for walking/bicycling trips and minutes. The results for the sociodemographic variables vary across the main and follow-up study results in Table 4. The signand-significance patterns of the employment status, age variables, household size, and presence of minor in the household are particularly different across main and follow-up results for some travel outcomes in Table 4. Conversely, the relationship of IDTV with vehicle holdings and income is somewhat stable across the main and follow-up results. It is also noteworthy that the difference in transit IDTV between Monday and other days of the week becomes insignificant after the light rail opening. Overall, the way that IDTV relates to survey participants' observable characteristics is stable for some variables but unstable for others after new light rail transit is introduced, suggesting a possibly complex link from the rail transit service to IDTV. 


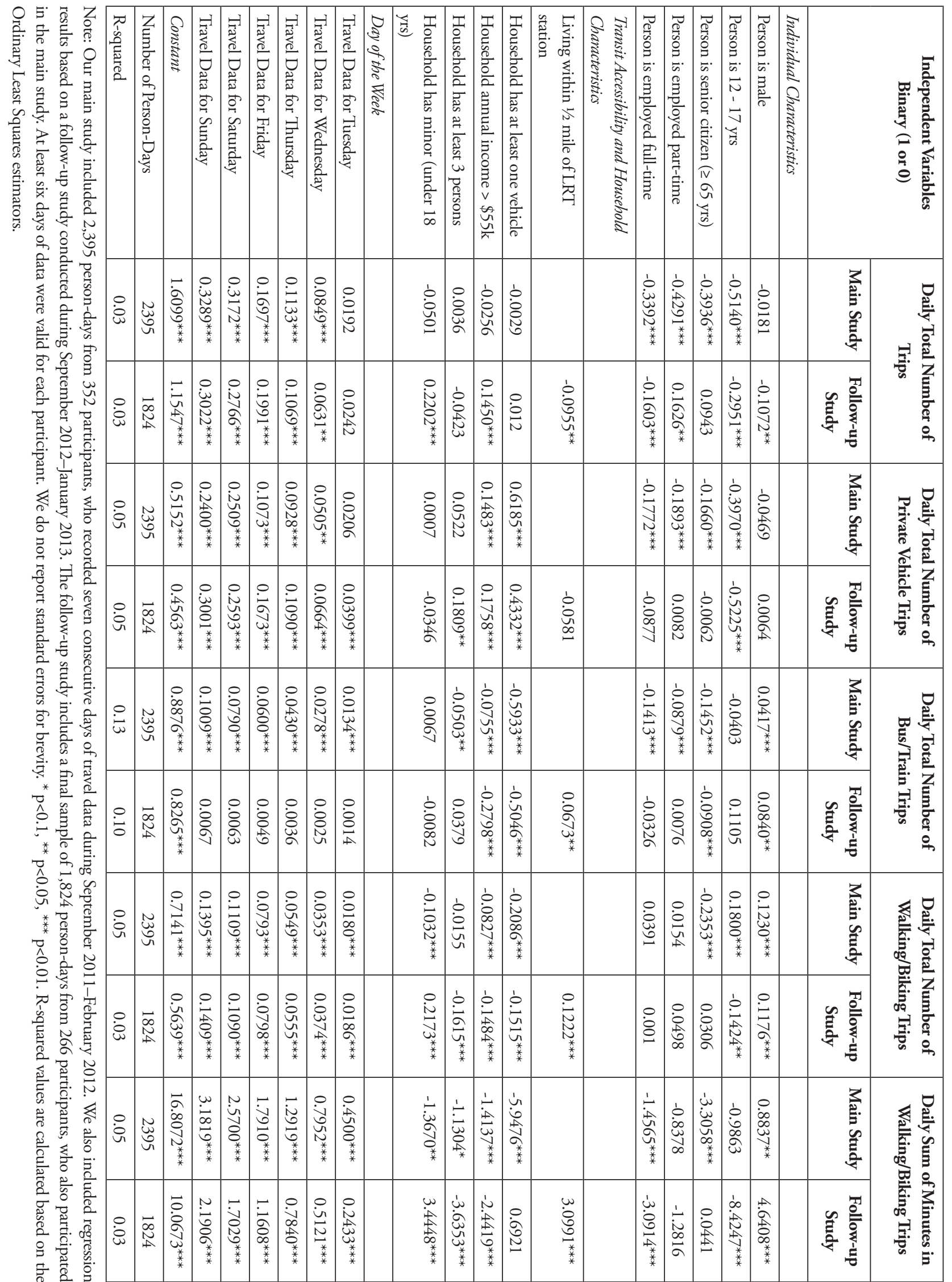


Overall, the results of the regression analysis are important for land use - travel researchers. First, IDTV is larger (compared to sample means) for non-automobile travel in our study sample. Second, the comparison between the main and follow-up studies shows that new light rail transit is associated with larger IDTV for non-motorized travel. Because IDTV varies across different travel outcomes (see Table 3), we believe that a strategy of weighting single-day surveys based on observable demographic characteristics will not be a successful approach to IDTV. The comparison of the main and follow-up results in Table 4 would lead to the same conclusion. For that reason, in the next section, we turn to a question of survey design: How many survey days should be used to measure different travel outcomes?

\subsection{Duration of survey and travel parameter estimates}

To better understand the influence of survey duration on travel parameter estimates, we conducted random sampling experiments. Our random sampling experiments are based on the master sample of 352 individuals. Figure 1 contrasts distributions of subsample means generated by the one through six days experiments following the Two-Step procedure (see Section 3.3); the seven-day means are denoted as $\mu_{\text {total }}$ (for daily total number of trips), $\mu_{\text {car }}$ (for daily total number of private vehicle trips), $\mu_{\text {pub }}$ (for daily total number of bus/train trips), $\mu_{\mathrm{wb}}$ (for daily total number of walking/biking trips), $\mu_{\mathrm{wbm}}$ (for daily sum of minutes in walking/biking trips). When the survey duration increased, the standard deviation of the distribution formed by the RS-generated subsample means decreased, and the subsample means converged to the mean calculated from the full seven-day data. For brevity, the standard deviations are not presented here. By imitating the confidence interval concept from statistics, we counted the number of experiments from which subsample means fell within the $\pm 2.5 \%$ and $\pm 5 \%$ bands to gauge the deviation of one-to-six-day means from the corresponding seven-day means.

Panel A illustrates distributions of subsample means for the daily total number of trips. Only $67 \%$ of the one-day subsample means fell within the $\pm 0.025^{*} \mu_{\text {total }}$ band; the percentage increased to $87 \%$ for two-day subsample means and at least $95 \%$ for a duration of three or more days. Panel B demonstrates simulation results from the daily total number of private vehicle trips. Only $56 \%$ of the one-day subsample means were within $\pm 0.025^{*} \mu_{\text {car }}$; the percentage increased to $78 \%$ for the two-day duration, $92 \%$ for the three-day duration and over 95\% for the duration of four or more days. As shown in Panel C, the intrapersonal day-to-day-variability in taking bus/train over the seven-day duration seemed hard to predict; only $17 \%$ of the subsample means from the one-day duration fell within the $\pm 0.025^{*} \mu_{\text {pub }}$ band; the proportion increased to $31 \%$ for the two-day duration, $36 \%$ for the three-day duration, $48 \%$ for the four-day duration, and $59 \%$ for the five-day duration; even the subsample means of the six-day duration had only a chance of $87 \%$ in falling within the $\pm 0.025^{*} \mu_{\text {pub }}$ band. The similar situation applies to the daily sum minutes in walking/biking trips, as demonstrated in Panel E; the proportion of subsample means falling within the $\pm 0.025^{*} \mu_{\mathrm{wbm}}$ was less than $95 \%$ for the duration from one to five days.

Expanding the bands to $\pm 5 \%$ of the seven-day means, we found that the proportion of subsample means within the band increased. For the daily total number of trips and daily total number of private vehicle trips, the proportions of one-day subsample means within the band were both over $90 \%$. However, for the bus/train and walk/biking variables, the one-day duration would nevertheless produce means that are very likely to fall outside the band.

These results can give suggestions about appropriate survey durations to measure trip frequencies for different trip types. Regarding the daily total number of trips and daily total number of private vehicle trips, three days of survey duration will very likely (over $90 \%$ chance) produce estimates that are close $( \pm 2.5 \%$ of seven-day mean; same for other travel metrics) to the estimates from the seven-day survey, which is consistent with findings by Jara-Díaz and Rosales-Salas (2015). Walking/biking trips will need at least five days of survey duration to produce estimates that are likely (about 90\% chance) to approach those from the seven-day survey. The longer survey durations are needed for walking/biking due in part to these trips being more discretionary (less mandatory) than private vehicle trips. Bus/train trips may be subject to the largest degree of uncertainty among all modes in terms of temporal trip re- 
petitiveness and frequency; estimates about bus/train trip frequencies from a less-than-seven-day survey duration may be associated with high risks of imprecision; such a finding, however, is in contrast with the analysis of Toronto-based 7-day survey by Buliung, Roorda, and Remmel (2008), in which transit was found to have the highest level of spatial repetition among all modes.

To gain additional insights on the robustness of results from our random sampling experiments, we have also tried two alternative sampling approaches: consecutive-day sampling and weekday-only sampling.

Table 5: Comparisons of results from alternative random sampling approaches

\begin{tabular}{|c|c|c|c|c|c|c|c|}
\hline & & & $\begin{array}{c}\text { Total } \\
\text { Trip } \\
\text { Count } \\
\end{array}$ & $\begin{array}{c}\text { Private } \\
\text { Vehicle Trip } \\
\text { Count } \\
\end{array}$ & $\begin{array}{l}\text { Bus/Train } \\
\text { Trip Count }\end{array}$ & $\begin{array}{c}\text { Walking/ } \\
\text { Biking Trip } \\
\text { Count } \\
\end{array}$ & $\begin{array}{c}\text { Walking/Bik- } \\
\text { ing Duration } \\
(\mathrm{min})\end{array}$ \\
\hline \multirow{13}{*}{$\begin{array}{c}\text { Random } \\
\text { Sampling } \\
\text { Experiments: } \\
\text { 7-Day (Opti- } \\
\text { mal) }\end{array}$} & \multicolumn{2}{|c|}{ 7-Day Mean $\mu$ 7day } & 3.9382 & 2.7424 & 0.2894 & 0.8768 & 15.4990 \\
\hline & \multirow{6}{*}{$\begin{array}{l}\text { Chance }(\%) \\
\text { Falling Within } \\
\pm 0.025^{*} \mu_{7 \text { day }}\end{array}$} & 1-Day & $67 \%$ & $56 \%$ & $17 \%$ & $36 \%$ & $30 \%$ \\
\hline & & 2-Day & $87 \%$ & $78 \%$ & $31 \%$ & $54 \%$ & $46 \%$ \\
\hline & & 3-Day & $96 \%$ & $92 \%$ & $36 \%$ & $68 \%$ & $61 \%$ \\
\hline & & 4-Day & $100 \%$ & $98 \%$ & $48 \%$ & $82 \%$ & $75 \%$ \\
\hline & & 5-Day & $100 \%$ & $100 \%$ & $59 \%$ & $94 \%$ & $89 \%$ \\
\hline & & 6-Day & $100 \%$ & $100 \%$ & $83 \%$ & $100 \%$ & $98 \%$ \\
\hline & \multirow{6}{*}{$\begin{array}{l}\text { Chance }(\%) \\
\text { Falling Within } \\
\pm 0.05^{*} \mu 7 \text { day }\end{array}$} & 1-Day & $95 \%$ & $90 \%$ & $53 \%$ & $64 \%$ & $55 \%$ \\
\hline & & 2-Day & $100 \%$ & $98 \%$ & $64 \%$ & $86 \%$ & $78 \%$ \\
\hline & & 3-Day & $100 \%$ & $100 \%$ & $81 \%$ & $96 \%$ & $91 \%$ \\
\hline & & 4-Day & $100 \%$ & $100 \%$ & $92 \%$ & $99 \%$ & $98 \%$ \\
\hline & & 5-Day & $100 \%$ & $100 \%$ & $99 \%$ & $100 \%$ & $100 \%$ \\
\hline & & 6-Day & $100 \%$ & $100 \%$ & $53 \%$ & $100 \%$ & $100 \%$ \\
\hline \multirow{13}{*}{$\begin{array}{c}\text { Random } \\
\text { Sampling } \\
\text { Experiments: } \\
\text { 7-Day } \\
\text { (Consecutive- } \\
\text { Day) }\end{array}$} & \multicolumn{2}{|c|}{ 7-Day Mean $\mu$ 7day } & 3.9382 & 2.7424 & 0.2894 & 0.8768 & 15.4990 \\
\hline & \multirow{6}{*}{$\begin{array}{l}\text { Chance (\%) } \\
\text { Falling Within } \\
\pm 0.025^{*} \mu 7 \text { day }\end{array}$} & 1-Day & $67 \%$ & $56 \%$ & $17 \%$ & $36 \%$ & $30 \%$ \\
\hline & & 2-Day & $82 \%$ & $72 \%$ & $22 \%$ & $51 \%$ & $45 \%$ \\
\hline & & 3-Day & $91 \%$ & $71 \%$ & $28 \%$ & $61 \%$ & $59 \%$ \\
\hline & & 4-Day & $95 \%$ & $67 \%$ & $32 \%$ & $81 \%$ & $77 \%$ \\
\hline & & 5-Day & $99 \%$ & $94 \%$ & $52 \%$ & $91 \%$ & $87 \%$ \\
\hline & & 6-Day & $100 \%$ & $100 \%$ & $85 \%$ & $100 \%$ & $99 \%$ \\
\hline & \multirow{6}{*}{ 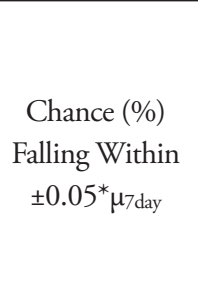 } & 1-Day & $95 \%$ & $90 \%$ & $33 \%$ & $64 \%$ & $55 \%$ \\
\hline & & 2-Day & $99 \%$ & $98 \%$ & $44 \%$ & $86 \%$ & $76 \%$ \\
\hline & & 3-Day & $100 \%$ & $98 \%$ & $52 \%$ & $94 \%$ & $90 \%$ \\
\hline & & 4-Day & $100 \%$ & $100 \%$ & $58 \%$ & $99 \%$ & $98 \%$ \\
\hline & & 5-Day & $100 \%$ & $100 \%$ & $84 \%$ & $100 \%$ & $100 \%$ \\
\hline & & 6-Day & $100 \%$ & $100 \%$ & $100 \%$ & $100 \%$ & $100 \%$ \\
\hline \multirow{9}{*}{$\begin{array}{l}\text { Random } \\
\text { Sampling } \\
\text { Experiments: } \\
\text { Weekday- } \\
\text { Only }\end{array}$} & \multicolumn{2}{|c|}{ 5-Day Mean $\mu_{\text {weekday }}$} & 4.0110 & 2.6835 & 0.3432 & 0.9541 & 15.9466 \\
\hline & \multirow{4}{*}{$\begin{array}{c}\text { Chance }(\%) \\
\text { Falling Within } \\
\pm 0.025^{*} \mu_{\text {weekday }}\end{array}$} & 1-Day & $73 \%$ & $62 \%$ & $23 \%$ & $47 \%$ & $35 \%$ \\
\hline & & 2-Day & $95 \%$ & $87 \%$ & $36 \%$ & $67 \%$ & $55 \%$ \\
\hline & & 3-Day & $99 \%$ & $97 \%$ & $55 \%$ & $87 \%$ & $75 \%$ \\
\hline & & 4-Day & $100 \%$ & $100 \%$ & $78 \%$ & $99 \%$ & $95 \%$ \\
\hline & \multirow{4}{*}{$\begin{array}{l}\text { Chance }(\%) \\
\text { Falling Within } \\
\pm 0.05^{*} \mu_{\text {weekday }}\end{array}$} & 1-Day & $98 \%$ & $94 \%$ & $45 \%$ & $79 \%$ & $64 \%$ \\
\hline & & 2-Day & $100 \%$ & $100 \%$ & $67 \%$ & $95 \%$ & $87 \%$ \\
\hline & & 3-Day & $100 \%$ & $100 \%$ & $87 \%$ & $100 \%$ & $98 \%$ \\
\hline & & 4-Day & $100 \%$ & $100 \%$ & $98 \%$ & $100 \%$ & $100 \%$ \\
\hline
\end{tabular}


The 2-to-6-day subsamples drawn from the consecutive-day sampling approach are those in which the survey days for each of the participants are consecutive based on his/her original reporting sequence. The distribution of the subsample means ${ }^{7}$ from this approach is similar to the optimal approach regarding shape and magnitude of spread. As shown in Table 5, the consecutive-day approach produces similar percentages to the optimal approach. The above similarities may be because our results are not subject to the considerable threat of reporting fatigue.

We performed the weekday-only sampling due to the consideration that travel behavior on Saturdays and Sundays might be different from that during the weekdays. Our random sampling experiments (1-4 days) were applied to five weekdays only. As shown in Table 5, there are some slight differences between weekday-means and their 7-day counterparts. Due to smaller variability in travel during weekdays than during weekends (as shown in the FGLS analysis), surveys of 1-to-4-weekday duration produce estimates that are closer to population means compared to surveys of the same duration for the whole week.

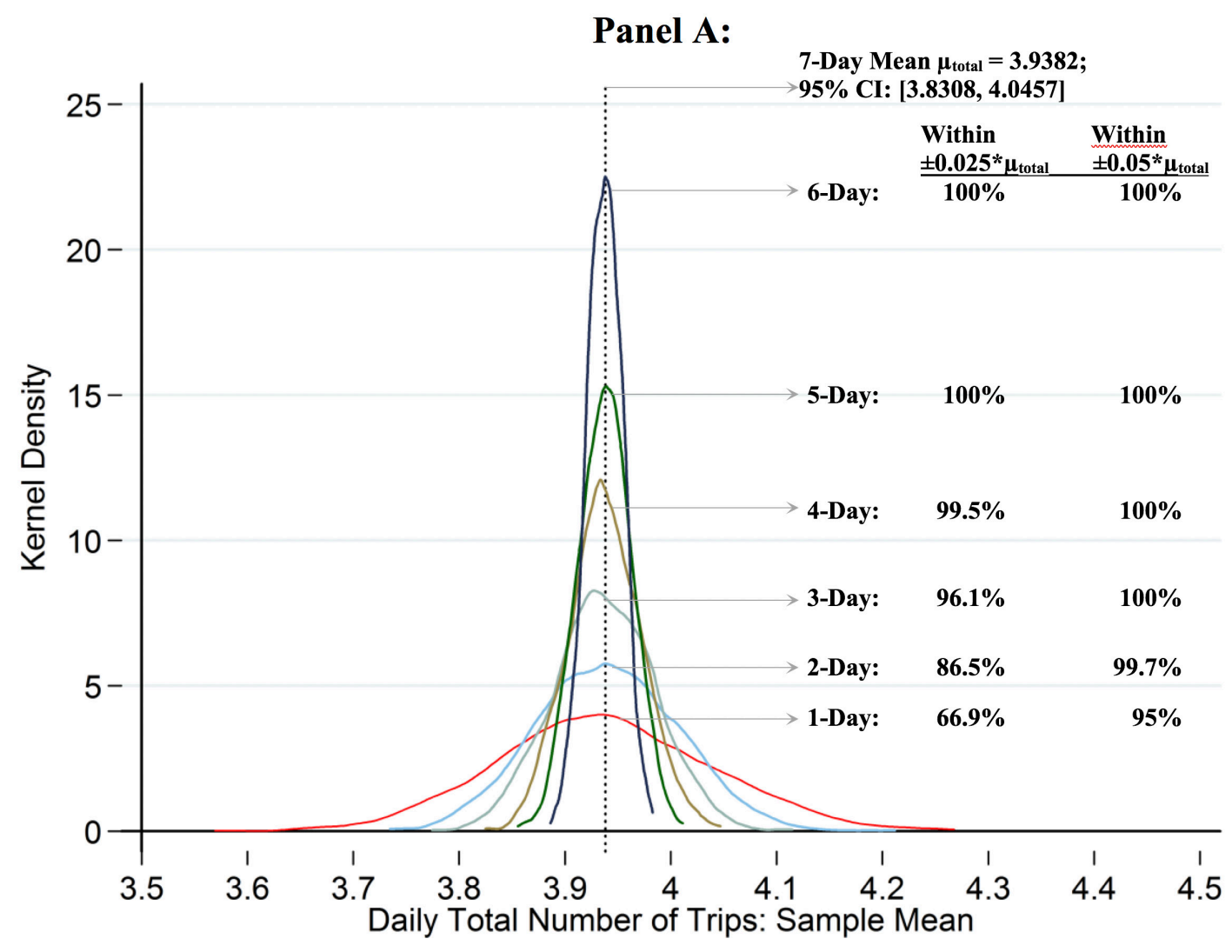

${ }^{7}$ For brevity, figures about the distributions are not reported. They are available upon request. 
Panel B:

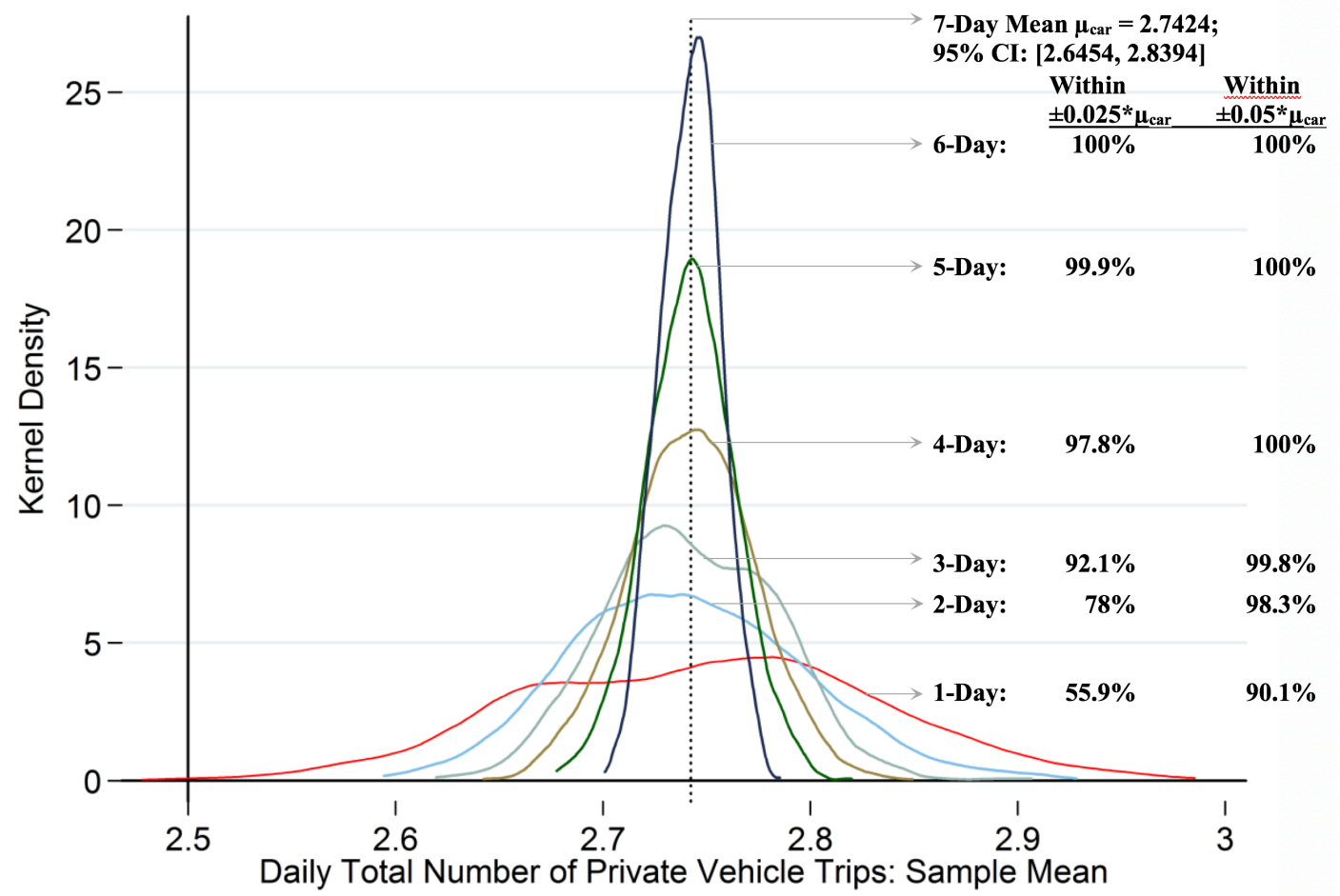

Panel C:

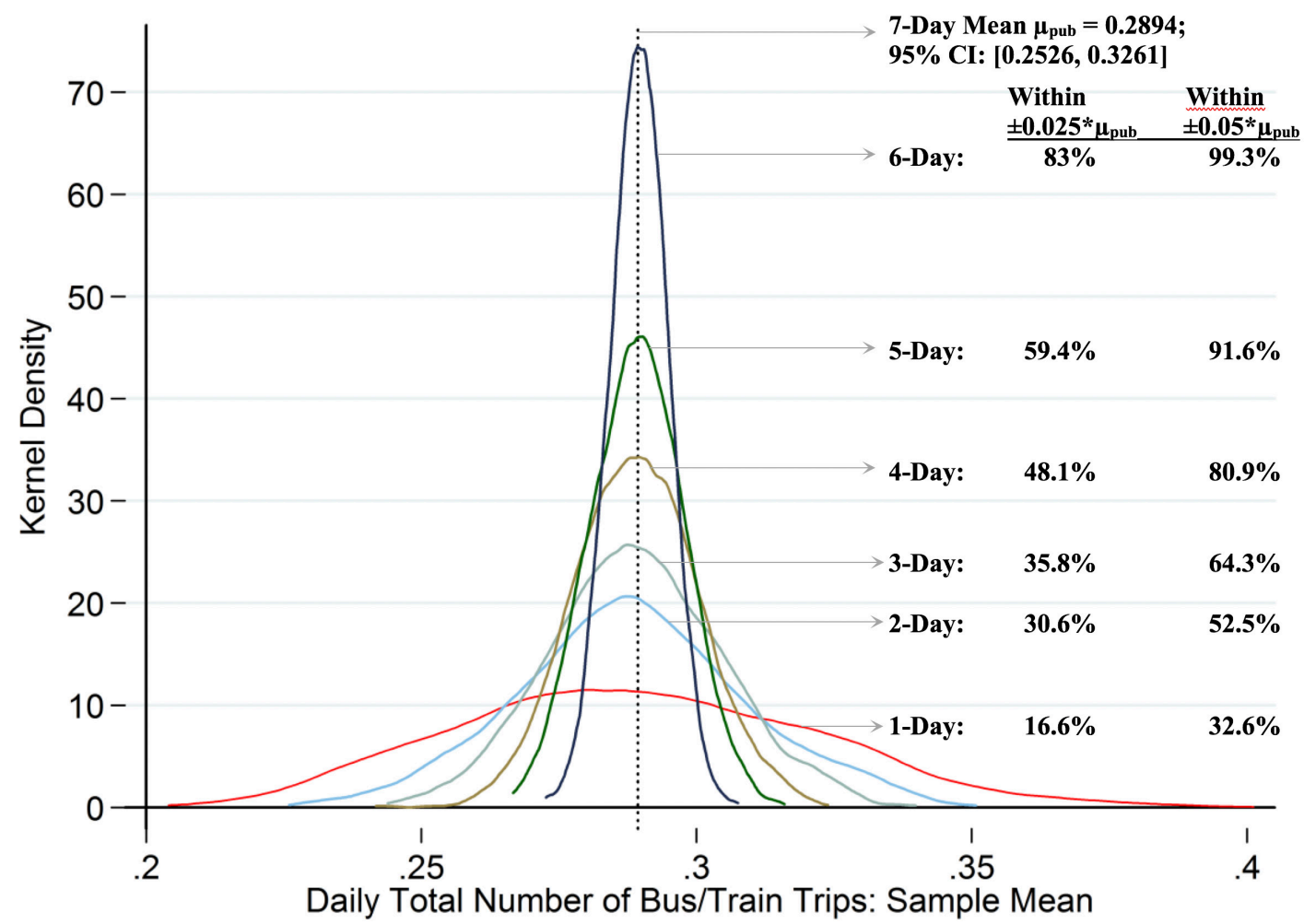




\section{Panel D:}

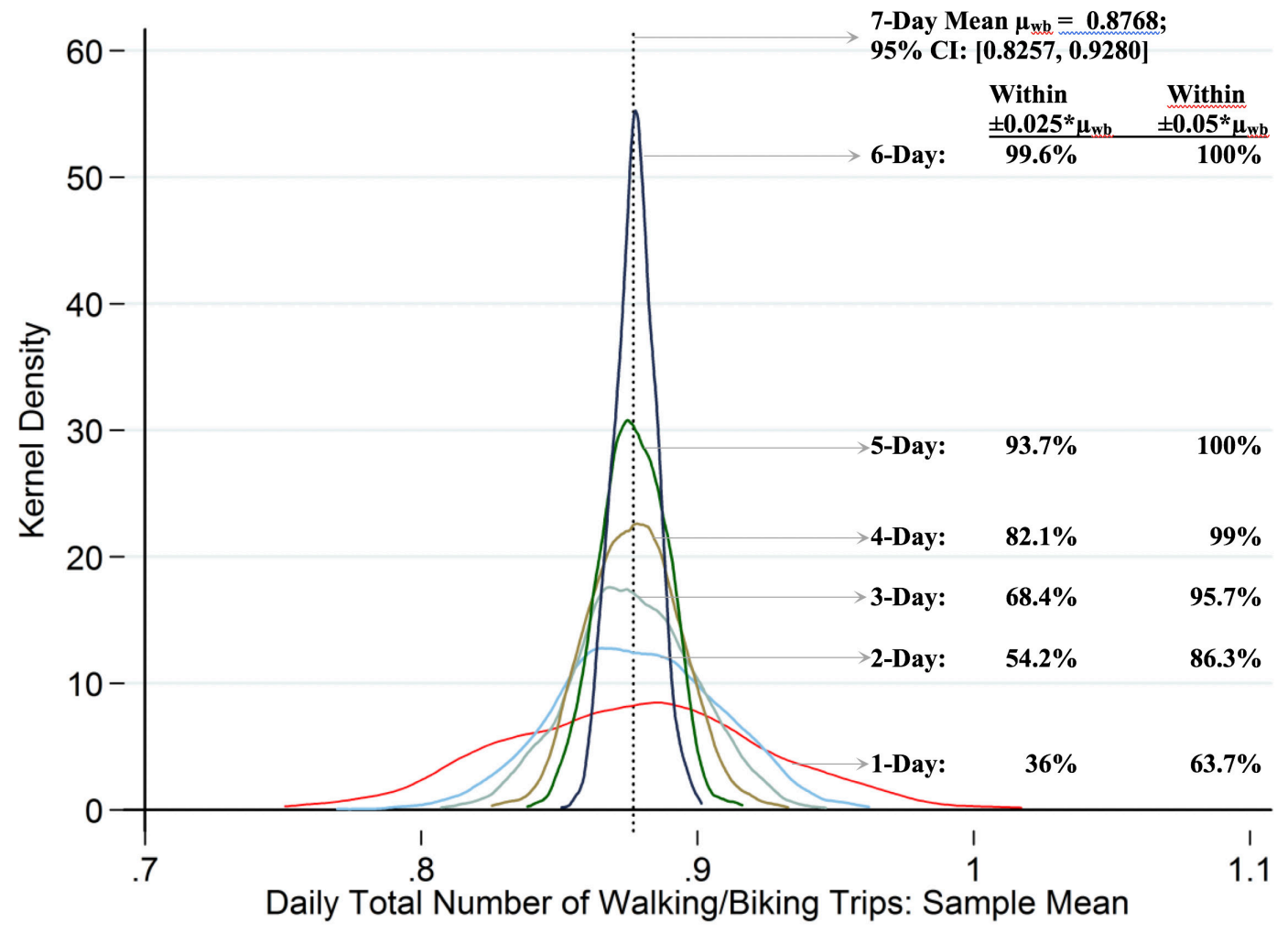

Panel E:

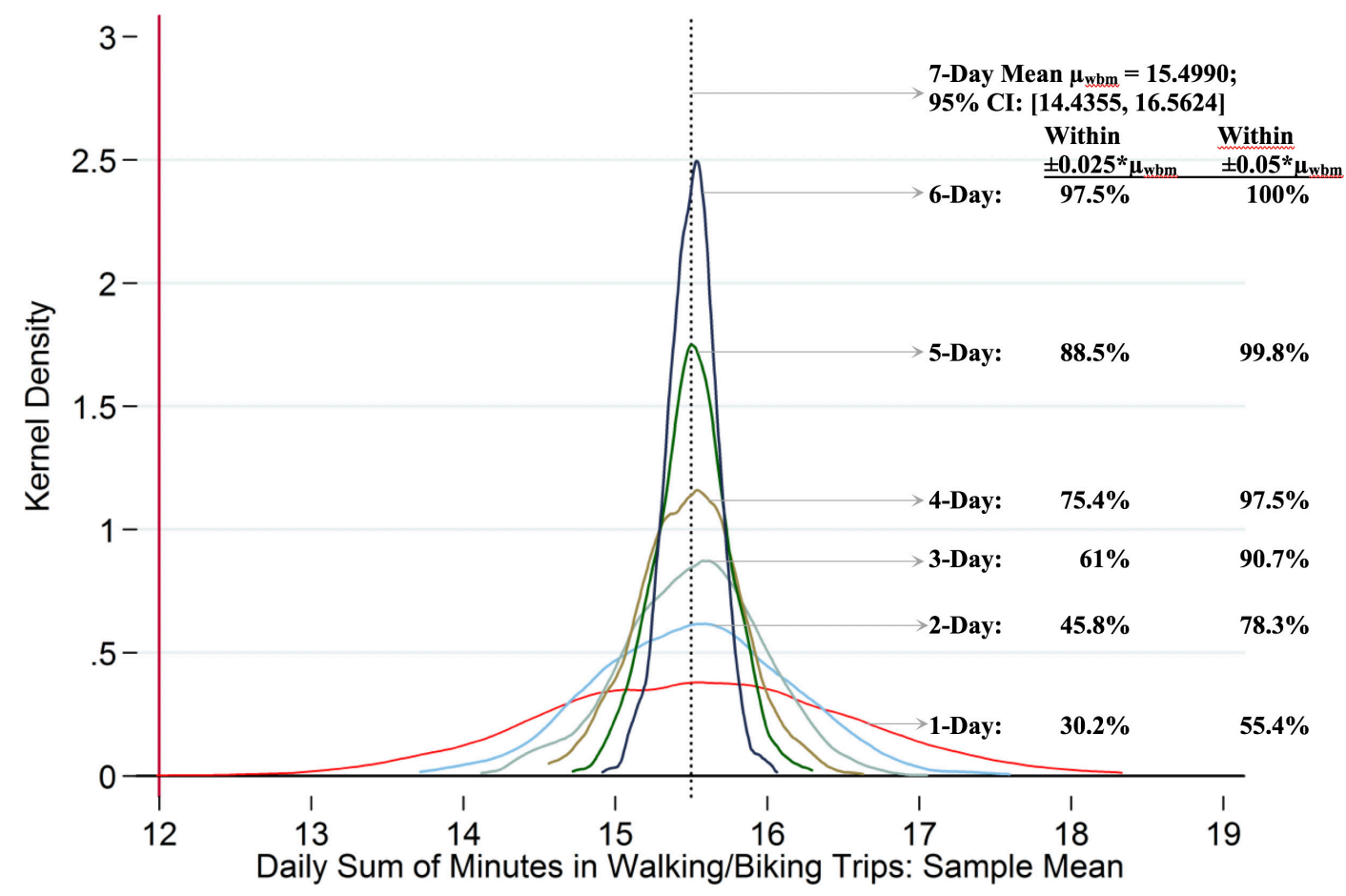

Figure 1: Distribution of sample means from random sampling experiments 


\section{$5 \quad$ Discussions and conclusions}

Our analysis of the Los Angeles seven-day travel data reveals that travel activities of an individual may not be repetitive on a daily basis and are not regular. Our measurement of the IDTV is consistent with the Atlanta study by Elango et al. (2007); in our study, the IDTV in the private vehicle mode is equal to $39 \%$ of the sample mean, compared to approximately $40 \%$ in the Atlanta sample. ${ }^{8}$ The observed characteristics, such as socio-demographics and the day of the week, can only explain a small portion of the intrapersonal day-to-day travel variability, leaving the majority of the variability difficult to explain and predict. The results from our linear models and random sampling experiments are largely consistent with previous findings of Pas (1986), Stopher et al. (2008), and Stopher and Zhang (2011) and raise serious concerns regarding the one-day travel survey convention among transportation professionals and policymakers.

We further challenged single-day travel surveys by making new findings. First, non-motorized travel is particularly sensitive to inter-day within-person variations in our data. Second, the provision of new light rail transit is associated with IDTV, and some of the associations between individual demographics and IDTV are not stable before versus after light rail is introduced. Third, given the standards for precision that we use in Section 4, the number of days appropriate for travel surveys varies across travel modes.

We recommend that surveys which aim to reveal trip frequency information from a wide range of modes consider shifting from the conventional one-day approach towards the multi-day approach. The multi-day surveys are especially important to capture modes such as transit, biking, and walking, which need more days of data than car travel based on our RS experiments. Multi-day surveys may be increasingly promising with new instruments such as GPS and smartphone apps that might reduce multi-day data collection burdens and cost.

Our design of the RS experiments is possibly subject to the following limitations. First, considering the low-income and non-white character of our study area, we are unable to determine whether our results are generalizable to other cities with different socio-demographic characteristics, partly due to the lack of available previous studies to compare with; the generalizability might be further compromised by the low response rate. Second, our analysis is confined to the limited number of travel metrics (mainly trip counts) derived from trip logs; a number of other variables, such as the trip purpose and the time of day when a trip takes place, which are usually included in the conventional travel diaries, are not included in our analysis.

However, our study makes unique contributions to the literature beyond challenging the practice of single-day travel surveys. How to determine the duration of a travel survey has been a salient but unanswered question to transportation researchers and practitioners for decades. Our study has presented a novel way to directly address this question by unlocking the potential of the random sampling experiments.

Future research may consider applying the random sampling technique to more multi-day travel surveys with different socio-demographic settings and new survey instruments such as smartphone apps and GPS (Shen \& Stopher, 2014) to shed light on the generalizability of findings pertinent to intrapersonal day-to-day variability, determination of survey duration, and the tradeoff between costs and benefits of multi-day surveys (e.g., comparing results between a 7-day sample and a larger-size 1-day sample which would cost the same for collection). It is important to acknowledge the influence of survey burden on response quality (Ampt, 2003; Axhausen et al., 2002; Jones \& Clarke, 1988; Stopher \& Greaves, 2007; Stopher et al., 2008); future researchers may consider expanding this track of work by comparing travel parameter estimates between travel logs and the conventional travel diaries.

${ }^{8}$ Elango et al. (2007) reported that the average variability in the daily private vehicle trips was 3 trips; from their Figure 1, we estimated that their average daily private vehicle trip was approximately 7 trips. 


\section{Acknowledgements}

This research was supported by the following organizations: National Science Foundation (Award\#: 1461766), Haynes Foundation, Lincoln Institute of Land Policy, San Jose State Mineta Transportation Institute, Southern California Association of Governments, University of California Transportation Center, University of California Multi-Campus Research Program on Sustainable Transportation, and the University of Southern California Lusk Center for Real Estate. During data collection and processing, we received assistance from numerous colleagues, particularly Steve Spears, Dongwoo Yang, Gavin Ferguson, Hsin-Ping Hsu, and Carolina Sarmiento; we are grateful for their assistance. Thanks to the colleagues who provided valuable comments during the Annual Meetings of the Transportation Research Board. 


\section{References}

Ampt, E. S. (2003). Respondent burden. In P. Jones \& P. R. Stopher (Eds.), Transport survey quality and innovation (pp. 507-521). Bingley, UK: Emerald Group Publishing Limited.

Axhausen, K. W., Zimmermann, A., Schönfelder, S., Rindsfüser, G., \& Haupt, T. (2002). Observing the rhythms of daily life: A six-week travel diary. Transportation, 29(2), 95-124.

Barnard, P. O. (1984). Use of an activity diary survey to examine travel and activity reporting in a home interview survey. Paper presented at the 9th Australian Transport Research Forum, Adelaide, May $15-16$.

Bayarma, A., Kitamura, R., \& Susilo, Y. O. (2007). Recurrence of daily travel patterns: Stochastic process approach to multiday travel behavior. Transportation Research Record: Journal of the Transportation Research Board, 2021(1), 55-63.

Bhat, C. R., Frusti, T., Zhao, H., Schönfelder, S., \& Axhausen, K. W. (2004). Intershopping duration: An analysis using multiweek data. Transportation Research Part B: Methodological, 38(1), 39-60.

Bohte, W., \& Maat, K. (2009). Deriving and validating trip purposes and travel modes for multi-day GPS-based travel surveys: A large-scale application in the Netherlands. Transportation Research Part C: Emerging Technologies, 17(3), 285-297.

Buliung, R. N., Roorda, M. J., \& Remmel, T. K. (2008). Exploring spatial variety in patterns of activitytravel behavior: Initial results from the Toronto Travel-Activity Panel Survey (TTAPS). Transportation, 35(6), 697-722.

California Department of Transportation. (2013). 2010-2012 California household travel survey final report. Retrieved from http://www.dot.ca.gov/hq/tsip/FinalReport.pdf

Carmel, Y., Paz, S., Jahashan, F., \& Shoshany, M. (2009). Assessing fire risk using Monte Carlo simulations of fire spread. Forest Ecology and Management, 257(1), 370-377.

Chang, N.-B., Parvathinathan, G., \& Breeden, J. B. (2008). Combining GIS with fuzzy multicriteria decision-making for landfill siting in a fast-growing urban region. Journal of Environmental Management, 87(1), 139-153.

Chen, A., Yang, H., Lo, H. K., \& Tang, W. H. (1999). A capacity related reliability for transportation networks. Journal of Advanced Transportation, 33(2), 183-200.

Dill, J., \& Broach, J. (2014). Travel to common destinations: An exploration using multiday GPS data. Transportation Research Record: Journal of the Transportation Research Board, 2413(-1), 84-91. doi:10.3141/2413-09.

Elango, V. V., Guensler, R., \& Ogle, J. (2007). Day-to-day travel variability in the Commute Atlanta, Georgia, study. Transportation Research Record: Journal of the Transportation Research Board, 2014(-1), $39-49$.

Golob, T. F., \& Meurs, H. (1986). Biases in response over time in a seven-day travel diary. Transportation, 13(2), 163-181.

Goodwin, P. B. (1978). Intensity of car use in Oxford. Traffic engineering and control, 19(11), 514-517.

Hanson, S. (1982). The determinants of daily travel-activity patterns: Relative location and sociodemographic factors. Urban Geography, 3(3), 179-202.

Hanson, S., \& Hanson, P. (1981). The impact of married women's employment on household travel patterns: A Swedish example. Transportation, 10(2), 165-183.

Hanson, S., \& Huff, J. O. (1981). Assessing day-to-day variability in complex travel patterns. Transportation Research Record, 891, 18-24.

Harrison, B. (1986). Electronic road pricing in Hong Kong III: Estimating and evaluating the effects. Traffic Engineering \& Control, 27(1), 13-18.

Harvey, A. S. (1993). Guidelines for time use data collection. Social Indicators Research, 30(2-3), $197-$ 228. 
Hong, A., Boarnet, M. G., \& Houston, D. (2016). New light rail transit and active travel: A longitudinal study. Transportation Research Part A: Policy and Practice, 92, 131-144.

Houston, D., Boarnet, M. G., Ferguson, G., \& Spears, S. (2015). Can compact rail transit corridors transform the automobile city? Planning for more sustainable travel in Los Angeles. Urban Studies, 52(5), 938-959.

Houston, D., Luong, T. T., \& Boarnet, M. G. (2014). Tracking daily travel; Assessing discrepancies between GPS-derived and self-reported travel patterns. Transportation Research Part C: Emerging Technologies, 48, 97-108.

Jara-Díaz, S., \& Rosales-Salas, J. (2015). Understanding time use: Daily or weekly data? Transportation Research Part A: Policy and Practice, 76, 38-57.

Jones, P., \& Clarke, M. (1988). The significance and measurement of variability in travel behavior. Transportation, 15(1), 65-87.

Karlsruhe Institute of Technology. (2015). MOP_The German mobility plan. Karlsruhe, Germany: Karlsruhe Institute of Technology.

Kennedy, P. (2008). A guide to econometrics (6th ed.). Hoboken, NJ: Blackwell Publishing Ltd.

Li, W. (1994). Reliability assessment of electrical power systems using Monte Carlo methods. New York: Springer.

Löchl, M., Axhausen, K., \& Schönfelder, S. (2005). Analyzing Swiss longitudinal travel data. Paper presented at the 5th Swiss Transport Research Conference, Monte Verità, March.

Marble, D. F., Hanson, P. O., \& Hanson, S. (1972). Household travel behavior study: Field operations and questionnaires. Evanston, IL: Transportation Center, Northwestern University.

Michigan Department of Transportation. (2005). 2004-2005 Comprehensive household travel data collection program: MI travel counts. Retrieved from http://www.michigan.gov/documents/MDOT_travelcounts_results_Final_Report_142283_7.pdf

Pas, E. I. (1983). A flexible and integrated methodology for analytical classification of daily travelactivity behavior. Transportation Science, 17(4), 405-429.

Pas, E. I. (1986). Multiday samples, parameter estimation precision, and data collection costs for least squares regression trip-generation models. Environment and Planning A, 18(1), 73-87.

Pas, E. I. (1987). Intrapersonal variability and model goodness-of-fit. Transportation Research Part A: General, 21(6), 431-438.

Pas, E. I., \& Harvey, A. S. (1997). Time use research and travel demand analysis and modelling. In P. R. Stopher \& M. E. H. Lee-Gosselin (Eds.), Understanding travel behavior in an era of change. New York: Pergamon.

Pas, E. I., \& Koppelman, F. S. (1987). An examination of the determinants of day-to-day variability in individuals' urban travel behavior. Transportation, 14(1), 3-20. doi:10.1007/BF00172463

Pas, E. I., \& Sundar, S. (1995). Intrapersonal variability in daily urban travel behavior: Some additional evidence. Transportation, 22(2), 135-150.

Schlich, R., \& Axhausen, K. W. (2003). Habitual travel behavior: Evidence from a six-week travel diary. Transportation, 30(1), 13-36.

Shapcott, M. (1978). Comparison of the use of time in Reading, England, with time use in other countries. Transactions of the Martin Centre for Architectural and Urban Studies, 3, 231-257.

Shen, L., \& Stopher, P. R. (2014). Review of GPS travel survey and GPS data-processing methods. Transport Reviews, 34(3), 316-334.

Spears, S., Houston, D., \& Boarnet, M. G. (2013). Illuminating the unseen in transit use: A framework for examining the effect of attitudes and perceptions on travel behavior. Transportation Research Part A: Policy and Practice, 58, 40-53. 
STATA. (2017). Fit panel-data models by using GLS. Retrieved from https://www.stata.com/manuals13/ xtxtgls.pdf

Stopher, P. R. (2012). Collecting, managing, and assessing data using sample surveys. Cambridge, UK: Cambridge University Press.

Stopher, P. R., Clifford, E., \& Montes, M. (2008). Variability of travel over multiple days: Analysis of three panel waves. Transportation Research Record: Journal of the Transportation Research Board, 2054(1), 56-63.

Stopher, P. R., \& Greaves, S. P. (2007). Household travel surveys: Where are we going? Transportation Research Part A: Policy and Practice, 41(5), 367-381.

Stopher, P. R., Kockelman, K., Greaves, S. P., \& Clifford, E. (2008). Reducing burden and sample sizes in multiday household travel surveys. Transportation Research Record: Journal of the Transportation Research Board, 2064(-1), 12-18.

Stopher, P. R., \& Zhang, Y. (2011). Repetitiveness of daily travel. Transportation Research Record: Journal of the Transportation Research Board, 2230(1), 75-84.

Stopher, P. R., Zhang, Y., Armoogum, J., \& Madre, J.-L. (2011). National household travel surveys: The case for Australia. Paper presented at the 34th Australasian Transport Research Forum (ATRF), Adelaide, South Australia.

Tran, N. L., Chikaraishi, M., Zhang, J., \& Fujiwara, A. (2012). Exploring day-to-day variations in the bus usage behavior of motorcycle owners in hanoi. Procedia-Social and Behavioral Sciences, 43, 265-276.

UK Department of Transport. (2016). National travel survey statistics. Retrieved from https://www.gov. uk/government/collections/national-travel-survey-statistics

Venter, C. J., \& Joubert, J. W. (2013). Use of multisource global positioning system data to characterize multiday driving patterns and fuel usage in a large urban region. Transportation Research Record: Journal of the Transportation Research Board, 2338(1), 1-10.

Wooldridge, J. M. (2006; p 424-426). Introductory econometrics: A modern approach (3rd ed). Masson, $\mathrm{OH}$ : Thomson South-Western.

Xian, G., \& Crane, M. (2005). Assessments of urban growth in the Tampa Bay watershed using remote sensing data. Remote Sensing of Environment, 97(2), 203-215. 


\section{Appendix}

Appendix available as a supplemental file at www.jtlu.org/index.php/jtlu/article/view/984. 